\title{
A three-dimension finite element analysis to evaluate the stress distribution in tooth supported 5 -unit intermediate abutment prosthesis with rigid and nonrigid connector
}

\author{
Ritesh Modi ${ }^{1}$, Shivani Kohli ${ }^{2}$, K. Rajeshwari ${ }^{3}$, Shekhar Bhatia ${ }^{4}$
}

Correspondence: Dr. Shivani Kohli

Email: drshivanidentist@gmail.com

\begin{abstract}
'Department of Prosthodontics, Eclavya Dental College and Hospital, Kotputli, Jaipur, Rajasthan, India, 2Department of Prosthodontics, MAHSA University, Kuala Lumpur, Malaysia,

${ }^{3}$ Department of Prosthodontics, KLE Society's Institute of Dental Sciences, Bengaluru, Karnataka, India, ${ }^{4}$ Division of Restorative Dentistry, School of Dentistry, International Medical University, Kuala Lumpur, Malaysia
\end{abstract}

\section{ABSTRACT}

Objective: The aim of the study is to evaluate the stress distribution in tooth supported 5-unit fixed partial denture (FPD) having tooth as pier abutment using rigid and nonrigid connectors respectively, under simultaneous and progressive loading. Material and Methods: The three-dimensional (3D) finite element program (ANSYS software) was used to construct the mathematical model. Two 5-unit FPD'S were simulated, one with rigid connector and another one with nonrigid connector. For analysis, each of these models were subjected to axial and oblique forces under progressive loading $(180,180,120,120,80 \mathrm{~N}$ force on first and second molars, premolars and canine respectively) and simultaneous loading $(100,100,100,100,100 \mathrm{~N}$ force on first and second molars, premolars and canine respectively). Results: The rigid and nonrigid connector design have effect on stress distribution in 5-unit FPDs with pier abutments. Conclusion: Oblique forces produce more stresses than vertical forces. Nonrigid connector resulted in decrease in stress at the level of prosthesis and increase in stress at the level of alveolar crest.

Key words: Connectors, finite element analysis, pier abutment, stress distribution, tooth supported

\section{INTRODUCTION}

In certain partially edentulous situations, the pattern of missing teeth may entail the use of fixed partial denture (FPD) utilizing pier abutment. ${ }^{[1,2]}$ Pier abutments have attracted the interest of clinicians and researchers worldwide. ${ }^{[3]}$ However, it has been reported that restoration of two missing teeth and an intermediate pier abutment with a rigid FPD is not an ideal treatment option. ${ }^{[1]}$ When an occlusal loads are applied to the retainers, the pier abutment may acts as a fulcrum leading to debonding of the less retentive terminal abutment and inevitably failure of the prosthesis.$^{[4-7]}$ Nonrigid connectors are suggested as a solution to these difficulties. ${ }^{[4,5,8]}$

Few studies have been done in the past, but have not been able to convincingly explain the role of tooth splinting in these situations and therefore there was a need to further study such situations to get conclusive results. ${ }^{[1,3]}$

The clinical evaluation of stresses within the components of the prosthesis or those transmitted to the surrounding tissues is nearly impossible. However, since the success of any dental prosthesis, is greatly

\footnotetext{
How to cite this article: Modi R, Kohli S, Rajeshwari K, Bhatia S. A three-dimension finite element analysis to evaluate the stress distribution in tooth supported 5-unit intermediate abutment prosthesis with rigid and nonrigid connector. Eur J Dent 2015;9:255-61. 
influenced by biomechanical factors, it has become essential to evaluate the stresses within the structures and those transferred to the surrounding tissues. ${ }^{[7]}$ Photoelastic models have been an important tool in the investigation of stress distribution in different systems; however, these models are constructed of plastic materials that cannot replicate precisely the behavior of intricate biological tissues they intend to simulate. ${ }^{[9]}$ Thus, the complex behavior and stress distribution patterns of enamel, dentin, pulp and nonlinear behavior of the periodontal ligament (PDL) cannot be simulated. ${ }^{[1]}$ Finite element analysis and modeling has opened new vistas in the field of dental biomechanics and has been able to replicate most of the dental structures varying in shapes and loading characteristics in three dimensions (3D). ${ }^{[10]}$

In spite of the recognition that biomechanics is the most predominant factor influencing the long-term success of a tooth supported system,,$^{[1,11]}$ the fundamental mechanics is still unclear, hence the need is felt to gain an insight into the stress distribution of tooth supported 5-unit FPD having tooth as pier abutment respectively using rigid and nonrigid connectors, under simultaneous and progressive loading.

\section{MATERIALS AND METHODS}

To analyze the stress distribution in order to predict the success or failure of the pier abutment prosthesis, the 3D finite element analysis software ANSYS (ANSYS Inc.; Houston, TX, USA) and the Pro/Engineer software (Parametric Technology Corporation, USA) was used to construct the mathematical model. ${ }^{[12]}$

As the study was directed to evaluate the stress distribution in a tooth/tooth supported pier abutment situation with the rigid and nonrigid connector design, a typical 5-unit pier abutment prosthesis was simulated with missing first premolar and first molar where second premolar acted as pier abutment in tooth/tooth supported prosthesis. Shillingburg's dovetail design was used to simulate the nonrigid connector. ${ }^{[13]}$ The natural teeth, PDL and mandibular bone were all simulated three dimensionally. ${ }^{[14,15]}$

Two FPD'S were simulated, one with rigid design and other with nonrigid designs. The nonrigid connector was kept at the distal surface of the pier abutment.

Design of the models used was as follows [Figure 1]:

- Natural tooth supported 5-unit intermediate

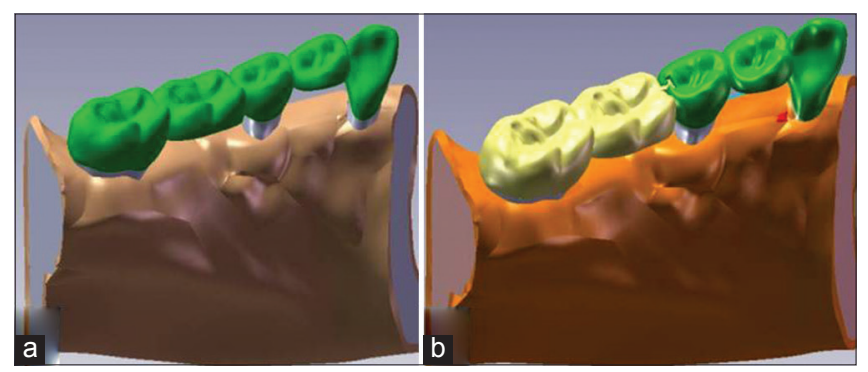

Figure 1: Natural tooth supported 5-unit intermediate abutment prosthesis with (a) rigid connector and (b) nonrigid connector

abutment prosthesis with rigid connector (Bridge-1)

- Natural tooth supported 5-unit intermediate abutment prosthesis with nonrigid connector (Bridge-2).

The study was carried out in three phases:

- Preprocessing and modeling

- Processing and meshing

- Postprocessing and analysis.

\section{Preprocessing and modeling}

The finite element method (FEM) is an innovative method used for resolution of impractical or intractable engineering problems; it has been used for many years to solve civil, mechanical, petroleum and structural engineering problems.

It has become a popular numerical method for stress analysis in dental biomechanical studies and many prosthodontic studies have been performed using this method.

A digital computer was used to model the various shapes and structures. The FEM consists of the division of each structure or continuum into local volumes or elements that are connected by their apices or nodes in order to form an interconnected mesh called the "finite element mesh." The elastic constants E (Young's modulus of elasticity) and $\mathrm{v}$ (Poison's ratio) of the modeled material were specified for each element. Systems of simultaneous equations were generated in each element throughout the structure which was called Mechanical FEA. It was used to simulate a real situation at points connected by springs that acted like a spider web so that changes in the local region were transmitted throughout the structure. The primary objective of a finite element analysis was to examine the response of a structure or component to certain loading conditions.

\section{Constructing the finite element model}

Conventionally the preprocessing involves the generation of points along $X, Y, Z$ axis on computer 
screen that was subsequently connected to obtain a line diagram on the tooth. Joining of lines created areas, and from these areas volumes were created. The smaller volumes were joined further to form an object. Thus in this study for the precise duplication of the anatomy of the models, the physical models of tooth and mandibular bone were scanned using high profile white light scanner to obtain the surface cloud data in steriolithographic (STL) format. This data was then transferred into PRO-E software for solid modeling of teeth, implant and bone.

Each of the models was constructed under following phases:

\section{Construction of the mandible geometry}

The point cloud obtained from scanning the mandibular bone was converted to 3D solid bone with its typical irregular geometry in the PRO-E software. The layers of cortical and cancellous bone were created. The dimensions were taken largely from the literature. ${ }^{[16]}$ Similarly, the solid models of the teeth were also created three-dimensionally, and their dimensions were matched to the average dimensions provided in the literature. The tooth preparation with respect to canine, premolar and molar teeth were carried out three dimensionally in the PRO-E program using current concepts of tooth preparation. ${ }^{[14]}$

The preparation was carried out internally into the solid tooth model to separate the metal ceramic crown with the prepared tooth. The first premolar and first molar pontic was designed as suggested in literature. ${ }^{[17]}$

\section{Construction of the final models}

Now the individually prepared teeth along with their crowns were aligned into the mandibular bone considering their mesio-distal and bucco-lingual inclination providing space for the premolar and molar pontics. The pontics were then aligned and joined to the adjacent crowns to their contact areas. Later all the crowns and the pontics were fused to form the rigid/nonrigid 5-unit pier abutment prosthesis. The distance between cemento enamel junction to alveolar crest was kept as $2 \mathrm{~mm}$.

The dovetail design was used to simulate the nonrigid connector that was kept parallel to the long axis of the second molar abutment. The surface of each root of the tooth was offset to create the PDL. The thickness of the PDL was kept as $0.25 \mathrm{~mm}$ assuming that the natural tooth has primary mobility within the border of the PDL membrane. ${ }^{[15,18]}$

\section{Processing and meshing}

Preprocessed models were subjected to processing by conversion of geometrical data into graphical data by the finite element software. This graphical data was then divided into smaller equal parts called elements by the technique called meshing. Following which the material properties were incorporated into the model referring the previous literature [Table 1]..$^{[1,19]}$

The nodes at the surface of the alveolar bone in the FEM models were fixed in all directions as the boundary condition. Materials used in this study were assumed to be homogeneous, isotropic and linearly elastic in nature. Elastic properties of materials (Youngs modulus (E) and Poisson's ratio (V) were determined from the literature. Each of the models contained 100897 nodes and 54447 elements.

\section{Postprocessing and analysis}

It was the third and final stage. For analysis, each of these models were subjected to axial and oblique forces under progressive and simultaneous loading. Progressive loading represents the average masticatory loading found in in vivo conditions, during which the values of the force decreases progressively from second molar to canine retainer that is, 180 $\mathrm{N}$ in second molar to $80 \mathrm{~N}$ in canine. ${ }^{[20,21]}$ During simultaneous loading, the values of the forces remains same from second molar to canine retainer that is, $100 \mathrm{~N}$ simultaneously in all the retainers. The forces were applied simultaneously on mandibular canine, premolars and first and second molars to simulate the average biting forces. ${ }^{[1]}$ The resultant stress values were then analyzed and compared, and constraints were applied throughout the entire perimeter and base of 3D model.

A total of four load situations were simulated, namely:

- Loading A: An axial load of 180, 180, 120, 120, 80 $\mathrm{N}$ force on first and second molars, premolars and canine respectively

- Loading B: An oblique load of 180, 180, 120, 120, $80 \mathrm{~N}$ force on first and second molars, premolars and canine respectively

\begin{tabular}{lcc} 
Table 1: Mechanical properties of materials \\
\hline Material & $\begin{array}{c}\text { Elastic modulus } \\
\text { (E) (Gpa) }\end{array}$ & $\begin{array}{c}\text { Poisson's } \\
\text { ratio (V) }\end{array}$ \\
Feldspathic porcelain & 82.8 & 0.35 \\
NiCr alloy & 206 & 0.33 \\
Dentin & 18 & 0.33 \\
Pulp tissue & 0.003 & 0.45 \\
Periodontal ligament & 0.069 & 0.45 \\
Cortical bone & 13.7 & 0.3 \\
Spongy bone & 1.37 & 0.3 \\
\hline
\end{tabular}


- Loading C: An axial load of 100, 100, 100, 100, 100 $\mathrm{N}$ force on first and second molars, premolars and canine respectively

- Loading D: An oblique load of 100, 100, 100, 100, $100 \mathrm{~N}$ force on first and second molars, premolars and canine respectively.

The oblique loads were applied in a direction of $12^{\circ}$ to the long axis. The oblique loads were applied by resolving them into vectors along the $Y$ and $Z$ axes using the principle in the Pythagoras theorem.

A total of eight load steps were run on the program that is, four load steps each on the two finite element models. The stresses were evaluated at the level of prosthesis, abutments and alveolar crest. Results for each loading were obtained as stress distribution colored images, and numerical values were recorded.

\section{RESULTS}

The stress distribution pattern obtained for both the types of bridges were as follows:

- Bridge-1: Natural tooth supported 5-unit intermediate abutment prosthesis with rigid connector under four different loading conditions [Figure 2]

- Bridge-2: Natural tooth supported 5-unit intermediate abutment prosthesis with nonrigid connector under four different loading conditions [Figure 3].

The deformation pattern obtained for both the types of bridges were as follows:

- Bridge-1: Natural tooth supported 5-unit intermediate abutment prosthesis with rigid

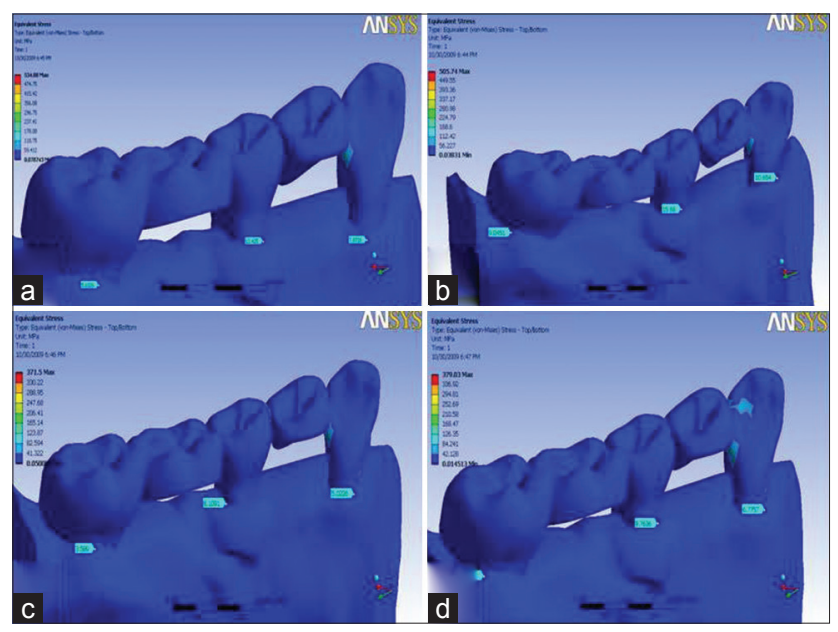

Figure 2: Stress distribution pattern obtained for Bridge-1 under different loading conditions (a) Loading A (b) Loading B (c) Loading C (d) Loading D connector under four different loading conditions [Figure 4]

- Bridge-2: Natural tooth supported 5-unit intermediate abutment prosthesis with nonrigid connector under four different loading conditions [Figure 5].

Table 2 shows the numerical values of peak stresses obtained, and Table 3 represents the resultant deformation with loading A, B, C and D on the pier abutment prosthesis.

Table 4 shows the peak stresses at the alveolar crest where T1-weighted is second molar abutment, T2-weighted is pier abutment, and T3-weighted is canine abutment.

All the resultant stress values were expressed in megapascals (MPa) and the deformation were expressed in millimeters $(\mathrm{mm})$.

\section{DISCUSSION}

According to Schillingburg et al. ${ }^{[13]}$ every restoration must be able to withstand the constant functional and parafunctional forces to which it is subjected. This is of particular significance when designing and fabricating a FPD, since the forces that would normally be absorbed by the missing tooth were transmitted, through the pontic connector and retainers, to the abutment teeth. These forces if exceeded beyond the physiologic limits of hard tissues can cause initial bone loss and failure of the prosthesis. ${ }^{[1]}$ Treatment planning should incorporate methods to reduce these stresses and minimize its initial and long-term effects. Direct experimental measurement of stress distribution at

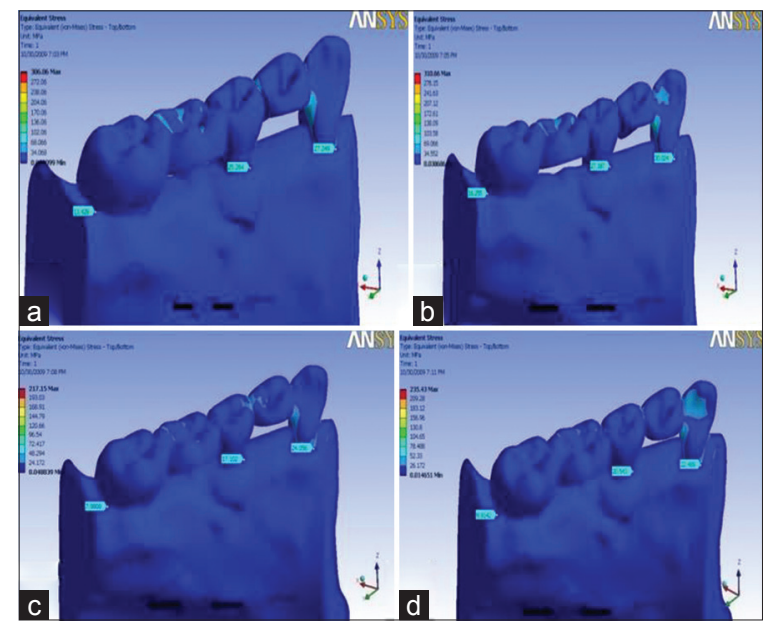

Figure 3: Stress distribution pattern obtained for Bridge-2 under different loading conditions (a) Loading A (b) Loading B (c) Loading C (d) Loading D 


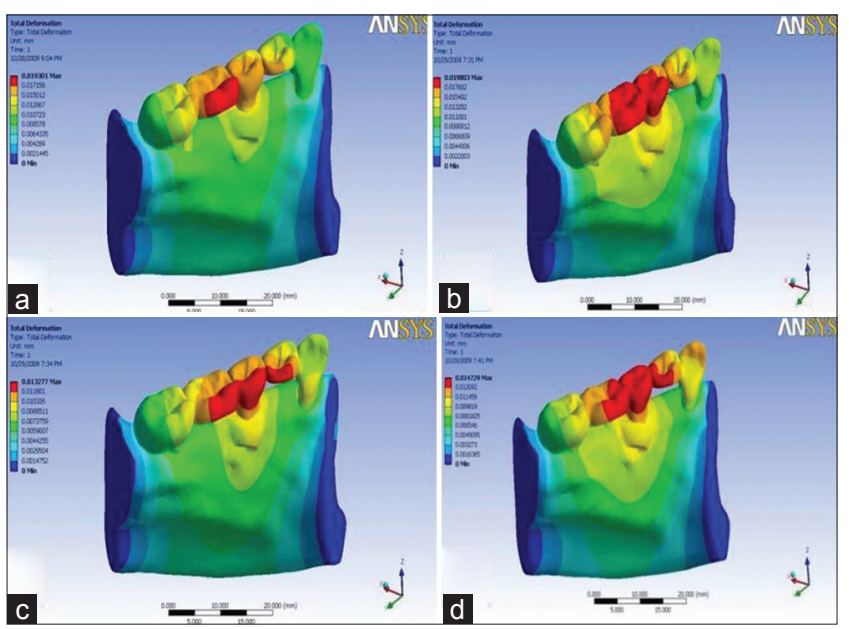

Figure 4: Deformation pattern obtained for Bridge-1 under different loading conditions (a) Loading A (b) Loading B (c) Loading C (d) Loading D

\begin{tabular}{lcccc}
\multicolumn{5}{l}{ Table 2: Peak stresses at the level of prosthesis } \\
\hline Stress & Loading A & Loading B & Loading C & Loading D \\
Bridge-1 & 72.5 & 86.19 & 50.27 & 61.48 \\
Bridge-2 & 71.37 & 76.55 & 48.29 & 60.57 \\
\hline
\end{tabular}

\begin{tabular}{lcccc}
\multicolumn{4}{l}{ Table 3: Deformation on pier abutment prosthesis } \\
\hline Deformation & Loading A & Loading B & Loading C & Loading D \\
Bridge-1 & 0.0193 & 0.0198 & 0.0132 & 0.0147 \\
Bridge-2 & 0.0191 & 0.0196 & 0.0129 & 0.0143 \\
\hline
\end{tabular}

these locations is difficult and thus there is the need for an analytic tool. ${ }^{[11]}$

Henceforth, the 3D FEM analysis was selected as the evaluation method in this investigation. As mentioned, the simulated prosthesis was loaded with progressive and simultaneous loading under axially and obliquely directed forces. The progressive loading represents the average masticatory loading as found in in vivo conditions and this was in accordance to the findings of Craig's, Powers and Sakaguchi, ${ }^{[20]}$ who mentioned that the occlusal forces were greater in the posterior region closest to the mandibular hinge axis and decrease from molar region to incisors. The numerical values were also derived from same authors that were $180 \mathrm{~N}$ for the molars, $120 \mathrm{~N}$ for premolars and $80 \mathrm{~N}$ for canine. This type of loading was used with an aim of simulating the normal masticatory forces more closely. ${ }^{[21]}$

During simultaneous loading the values of forces remained same from second molar to canine retainer that is, $100 \mathrm{~N}$ simultaneously in all the retainers which is in accordance with Selcuk Oruc, ${ }^{[1]}$ and it represents the uniformly distributed force all over the prosthesis. The authors mentioned that if the same standard value

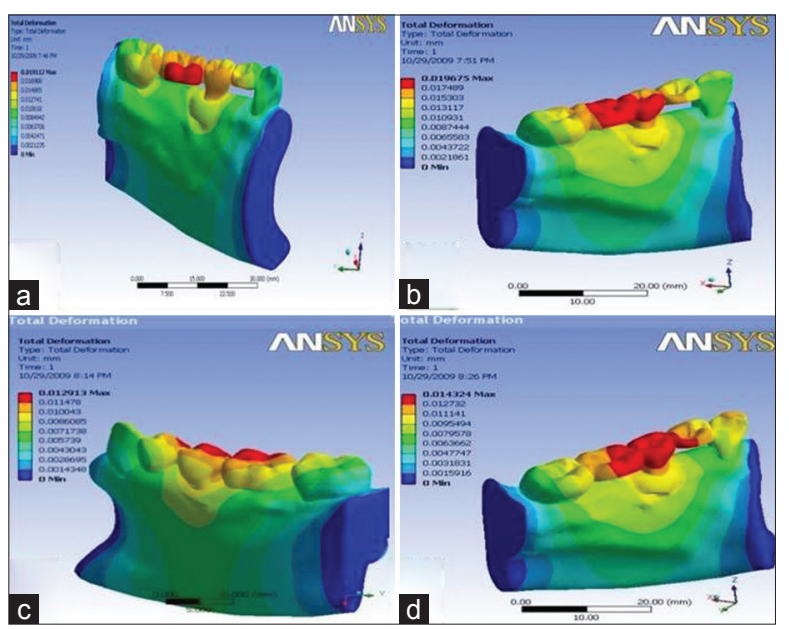

Figure 5: Deformation pattern obtained for Bridge-2 under different loading conditions (a) Loading A (b) Loading B (c) Loading C (d) Loading D

were simulated in each model, it was not necessary for this force to match in vivo conditions exactly if the conditions were compared qualitatively with each other. Lin et al. in their earlier finite element analysis studies also used the similar loading conditions for the purpose of comparison. ${ }^{[22]}$ According to them the magnitude of the occlusal force and occlusal contact location were more important factors than different connector designs in influencing the mechanical responses (stress values and distributions) of the teeth and alveolar bone. Oblique occlusal forces significantly increased the stress values of the splinting system when compared with axial occlusal forces. ${ }^{[8,12,13]}$

As in the present study, the magnitude of forces in case of progressive loading was more compared to simultaneous loading, the stresses obtained were also higher with progressive loading. It can be explained as, in case of progressive loading the average force which was applied to the prosthesis was $136 \mathrm{~N}(180+180+120+120+80=680$, and the average $680 / 5=136$ ) which was greater in magnitude than the simultaneous loading which was just 100 $\mathrm{N}(100+100+100+100+100=500$ and the average $500 / 5=100)$.

The result of present study showed, for example with loading type-B at the level of prosthesis the value of von misses stresses with tooth/tooth supported rigid prosthesis was $86.19 \mathrm{Mpa}$ whereas for tooth/tooth supported nonrigid prosthesis it was $76.55 \mathrm{Mpa}$. At the level of alveolar bone with loading type-B the value of von misses stresses in tooth/tooth supported rigid prosthesis at pier abutment was 15.6 Mpa whereas for tooth/tooth supported nonrigid prosthesis was $27.18 \mathrm{Mpa}$. Since the connectors represents the 
Modi, et al:: FEA to evaluate the stress distribution in tooth supported 5-unit prosthesis

\begin{tabular}{|c|c|c|c|c|c|c|c|c|c|c|c|c|}
\hline \multirow[t]{2}{*}{ Stress } & \multicolumn{3}{|c|}{ Loading A } & \multicolumn{3}{|c|}{ Loading B } & \multicolumn{3}{|c|}{ Loading C } & \multicolumn{3}{|c|}{ Loading D } \\
\hline & T1 & T2 & T3 & T1 & T2 & T3 & T1 & T2 & T3 & $\mathrm{T} 1$ & T2 & T3 \\
\hline Bridge-1 & 5.6 & 12.4 & 7.8 & 9 & 15.6 & 10.6 & 3.5 & 8.1 & 5.02 & 5.9 & 9.7 & 6.7 \\
\hline Bridge-2 & 13.4 & 25.2 & 27.2 & 16.2 & 27.18 & 30.02 & 7.9 & 17.1 & 24.05 & 9.9 & 20.4 & 22.4 \\
\hline
\end{tabular}

greatest stress concentration areas within FPDs, the placement of nonrigid connectors in these regions is recommended. ${ }^{[1]}$ Hence, nonrigid connectors were simulated in these regions in the current study.

\section{Comparison of stress distribution in the rigid and nonrigid connectors containing prosthesis}

The result of this study showed that the rigid and nonrigid connector designs have effects on the stress distributions in 5-unit FPDs with pier abutments. With the use of nonrigid connector, the stresses decreased slightly at the level of prosthesis that is, the connector region and the cervical margin of the prosthesis but, increased to a comparatively greater value at the level of alveolar bone [Tables 2 and 4]. For example with loading type-B at the level of prosthesis the value of von misses stresses with tooth/tooth supported rigid prosthesis was $86.19 \mathrm{Mpa}$ whereas it decreased slightly for the nonrigid prosthesis to a value 76.55 Mpa. At the level of alveolar bone with loading type-B the value of von misses stresses in tooth/tooth supported rigid prosthesis at pier abutment was 15.6 Mpa whereas it increased to a value 27.18 Mpa for nonrigid prosthesis.

Considering the discussed results, it can be definitely said that the use of nonrigid connector decreases stresses at the connector and cervical region of the prosthesis but at the cost of increasing the stresses at the alveolar crest which subsequently increases the chances of bone resorption. ${ }^{[3,5,7,23]}$

Misch recommended that in conventional fixed prostheses, the "male" portion of a nonrigid attachment is usually located on the mesial aspect of the posterior pontic, whereas the "female" portion is in the distal aspect of the natural pier abutment tooth and this prevents mesial drift from unseating the attachment. ${ }^{[24]}$

It was also observed in the study that the stresses at the second molar teeth were less as compared to canine and pier abutment teeth. This can be explained by the fact that as the molar tooth has a larger periodontal membrane area compared to the canine tooth, ${ }^{[10,18]}$ this may result in better stress distribution. This fact is earlier explained by Oruc et al..$^{[1]}$

\section{CONCLUSION}

Within the prosthesis nonrigid connector produced less stresses when compared to rigid connectors. Oblique forces produced more stresses as compared to vertical forces, and maximum stresses were observed at the canine abutment. Deformation was more at the pier abutment as compared to terminal abutments and also in rigid connectors as compared to nonrigid connectors. Forces at the level of the alveolar crest were more at the pier abutment, canine abutment and also in nonrigid connector as compared to rigid connector. In both the bridges, condition three (loading C) resulted in the lowest stress and deformations under vertical forces.

\section{Limitation of the study}

In the present study, as finite element analysis technique was used henceforth several assumptions were made regarding simulated structures. The structures in the model were all assumed to be homogenous, isotropic, and to possess linear elasticity. ${ }^{[25,26]}$ The properties of the materials modeled in this study, however, particularly the living tissues, were different. Importantly, the stress distribution patterns may have been different depending on the materials and properties assigned to each layer of the model which were used in the experiments.

The results were limited to the modeling procedure, thus giving only a general insight into the tendencies of biomechanical aspects under average conditions, without attempting to simulate individual clinical situations.

\section{REFERENCES}

1. Oruc S, Eraslan O, Tukay HA, Atay A. Stress analysis of effects of nonrigid connectors on fixed partial dentures with pier abutments. J Prosthet Dent 2008;99:185-92.

2. Badwaik PV, Pakhan AJ. Non-rigid connectors in fixed prosthodontics: Current concepts with a case report. J Indian Prosthet Soc 2005;5:99-102.

3. Savion I, Saucier CL, Rues S, Sadan A, Blatz M. The pier abutment: A review of the literature and a suggested mathematical model. Quintessence Int 2006;37:345-52.

4. Banerjee S, Khongshei A, Gupta T, Banerjee A. Non-rigid connector: The wand to allay the stresses on abutment. Contemp Clin Dent 2011;2:351-4.

5. Shillingburg HT Jr, Fisher DW. Nonrigid connectors for fixed partial 
dentures. J Am Dent Assoc 1973;87:1195-9.

6. Ferencz JL. The use of non-rigid connectors for long span ceramo-metal fixed partial dentures. N Y J Dent 1978;48:287-91.

7. Markley MR. Broken-stress principle and design in fixed bridge prosthesis. J Prosthet Dent 1951;1:416-23.

8. Rosenstiel S, Land M, Fujimoto J. Contemporary Fixed Prosthodontics. $4^{\text {th }}$ ed. St. Louis, Mo, USA: Mosby; 2006.

9. Moulding MB, Holland GA, Sulik WD. Photoelastic stress analysis of supporting alveolar bone as modified by nonrigid connectors. J Prosthet Dent 1988;59:263-74.

10. Awadalla HA, Azarbal M, Ismail YH, el-Ibiari W. Three-dimensional finite element stress analysis of a cantilever fixed partial denture. J Prosthet Dent 1992;68:243-8.

11. Lin CL, Wang JC, Kuo YC. Numerical simulation on the biomechanical interactions of tooth/implant-supported system under various occlusal forces with rigid/non-rigid connections. J Biomech 2006;39:453-63.

12. Lin CL, Wang JC. Nonlinear finite element analysis of a splinted implant with various connectors and occlusal forces. Int J Oral Maxillofac Implants 2003;18:331-40.

13. Schillingburg HT, Hobo S, Whitsett LD, Jacobi R, Brackett SE. Fundamentals of Fixed Prosthodontics. $3^{\text {rd }}$ ed. Chicago: Quintessence Publishing Co., Inc.; 1997.

14. Ozcelic T, Ersoy AE. An investigation of tooth/implant-supported fixed prosthesis designs with two different stress analysis methods: An in vitro study. J Prosthodont 2007;16:107-16.

15. Rees JS, Jacobsen PH. Elastic modulus of the periodontal ligament. Biomaterials 1997;18:995-9.

16. Wheeler RC. Dental Anatomy, Physiology and Occlusion. $9^{\text {th }}$ ed. Philadelphia, PA: Saunders; 1974.

17. Goodacre CJ, Campagni WV, Aquilino SA. Tooth preparations for complete crowns: An art form based on scientific principles. J Prosthet Dent 2001;85:363-76.

18. Pesun IJ, Steflik DE, Parr GE, Hanes PJ. Histological evaluation of the periodontium of abutment teeth in combination implant tooth fixed partial denture. Int J Oral Maxillofac Implants 1999;14:342-50.
19. Santiago Junior JF, Pellizzer EP, Verri FR, de Carvalho PS. Stress analysis in bone tissue around single implants with different diameters and veneering materials: A 3-D finite element study. Mater Sci Eng C Mater Biol Appl 2013;33:4700-14.

20. Powers JM, Sakaguchi RL. Craig's Restorative Dental Materials. $12^{\text {th }}$ ed. St. Louis: Mosby; 2006.

21. Jenkins GN. The Physiology and Biochemistry of Mouth. $4^{\text {th }}$ ed. Oxford: Blackwell Scientific Publication; 1978.

22. Lin CL, Wang JC, Chang WJ. Biomechanical interactions in tooth-implant-supported fixed partial dentures with variations in the number of splinted teeth and connector type: A finite element analysis. Clin Oral Implants Res 2008;19:107-17.

23. Holland GA, Sluder TB, Sutherland JK, White JT. A photoelastic analysis of the stress distribution in bone supporting fixed partial dentures of rigid and non rigid design. J Prosthet Dent 1980;44:616-23.

24. Misch CE. Dental Implant Prosthetics. St. Louis: Elsevier, Mosby; 2005. p. 189-90.

25. Moreira W, Hermann C, Pereira JT, Balbinoti JA, Tiossi R. A three-dimensional finite element study on the stress distribution pattern of two prosthetic abutments for external hexagon implants. Eur J Dent 2013;7:484-91.

26. Eraslan $\mathrm{O}$, Inan $\mathrm{O}$, Secilmis $\mathrm{A}$. The effect of framework design on stress distribution in implant-supported FPDs: A 3-D FEM study. Eur J Dent 2010;4:374-82.

\begin{tabular}{|l|l|}
\hline \multicolumn{2}{|c|}{ Access this article online } \\
\hline Quick Response Code: & Website: \\
\hline & www.eurjdent.com \\
\cline { 3 - 4 } & \\
\hline
\end{tabular}

